\title{
Ethidium bromide-induced demyelination of the sciatic nerve of adult Wistar rats
}

G. Riet-Correa ${ }^{1}$,

C.G. Fernandes ${ }^{1}$,

L.A.V. Pereira ${ }^{2}$

and D.L. Graça ${ }^{3}$

\section{Correspondence}

D.L. Graça

Departamento de Patologia

Universidade Federal de Santa M aria

97105-900 Santa Maria, RS

Brasil

Fax: + 55-55-220-8284

E-mail:dlgraca@ lince.hcv.ufsm.br

Research supported by CNPq and FAPERGS. Publication supported by FAPESP.

Received May 22, 2001

Accepted O ctober 16, 2001

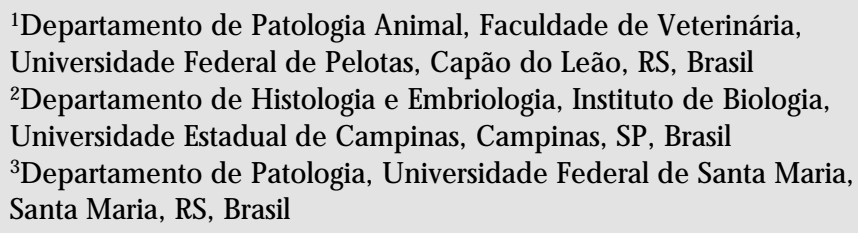

1Departamento de Patologia Animal, Faculdade de Veterinária, Universidade Federal de Pelotas, Capão do Leão, RS, Brasil 2D epartamento de Histologia e Embriologia, Instituto de Biologia, Universidade Estadual de Campinas, Campinas, SP, Brasil ${ }^{3}$ Departamento de Patologia, Universidade Federal de Santa Maria, Santa Maria, RS, Brasil

\section{Abstract}

Peripheral nerve ultrastructure was assessed after single or multiple local injections of the intercalating dye ethidium bromide. Thirty-four adult Wistar rats of both sexes were divided into five groups and maintained in a controlled environment with rat chow and water ad libitum throughout the experiment. The experimental animals were injected with $1 \mu \mathrm{l}$ of $0.1 \%$ ethidium bromide in $0.9 \%$ saline into the central third of the left sciatic nerve 1 (group 1), 2 (group 2), 4 (group 3 ), 6 (group 4) or 8 (group 5) times. In groups 2 to 5 the injections were made at 28-day intervals. Control animals received the same amount of $0.9 \%$ saline. The animals were killed at different times after injection: group 1 at 7 days ( 2 rats) and 15 days ( 2 rats); for groups 2 , 3,4 and 5, all rats were killed 10 days after the last injection and the lesions were investigated by light and transmission electron microscopy. In the acute lesions, intoxicated Schwann cells showed a vacuolated cytoplasm and separation of the sheaths from the axon. Myelin sheaths underwent progressive vesiculation and subsequent segmental demyelination. Myelin debris were withdrawn by macrophages and remyelination by Schwann cells was prominent. With the increase in the number of injections collagen fibers also increased in number and progressively enveloped smaller numbers of remyelinated axons composing new fascicles. Wallerian degeneration of fibers apparently not affected by ethidium bromide was more intense in the nerves from groups 4 and 5. The peripheral nerve repairs itself after demyelinating challenges with a profusion of collagen fibers and new fasciculations. This experimental model is valid to mimic recurrent demyelinating neuropathies.

\section{Introduction}

Ethidium bromide (EB) is an intercalating dye extensively used to induce demyelination in the central nervous system (CNS) (1). Demyelination follows the disappearance of neuroglial cells, chiefly astrocytes, in
Key words

- Demyelination

- Remyelination

- Sciatic nerve

- Ethidium bromide the early hours of intoxication $(2,3)$. The death of astrocytes makes a breach in the glial-limiting membrane through which Schwann cells invade the CNS and repair the lost myelin sheaths $(4,5)$.

Naked axons receive new myelin sheaths built by invading Schwann cells and remain- 
ing oligodendrocytes - the latter along the unaffected living tissue (2). Morphological recognition of the new sheaths is based on the thickness of the sheath and on the presence of a Schwann cell wrapping the axon and surrounded by a basal lamina associated with collagen fibers (1).

The peripheral nervous system (PNS) differs from the CNS in fundamental aspects, i.e., histological composition (6) and regenerating capacity $(7,8)$. In addition, Schwann cells are considered extremely industrious (9) and highly resistant to a broad span of spontaneous and experimental injuries (10). The aim of the present study was to observe Schwann cell reaction to local single and multiple EB injections and to document peripheral nerve responses to multiple challenges with the drug in order to validate this intoxication as an experimental model of demyelination in the PNS.

\section{Material and Methods}

Thirty-four adult Wistar rats of both sexes were maintained in individual polypropylene cages, with free access to ration and water. The rats were divided into five groups and submitted to intraneural EB injections (Table 1). Two animals from each group received an intraneural saline injection. Stance, gait and social behavior were recorded daily.

Demyelination was induced by single or multiple injections of $1 \mu \mathrm{l}$ of $0.1 \%$ EB in $0.15 \mathrm{M}$ saline along $8 \mathrm{~mm}$ on the middle

Table 1. Intraneural injections of ethidium bromide (EB) and saline in adult Wistar rats.

\begin{tabular}{lccc}
\hline Group & $\begin{array}{c}\text { Number of } \\
\text { EB-injected } \\
\text { animals }\end{array}$ & $\begin{array}{c}\text { Number of } \\
\text { saline-injected } \\
\text { animals }\end{array}$ & $\begin{array}{c}\text { Number of } \\
\text { injections }\end{array}$ \\
\hline 1 & 4 & 2 & 1 \\
2 & 5 & 2 & 2 \\
3 & 5 & 2 & 4 \\
4 & 5 & 2 & 6 \\
5 & 5 & 2 & 8
\end{tabular}

third of the left sciatic nerve. The multiple injections were made at 28-day intervals. All injections were made with a Hamilton syringe and the animals were anesthetized with fentanyl/hypnomidate (Johnson \& Johnson, São José dos Campos, SP, Brazil). The localization of the lesions was facilitated by a stitch in the adjacent semitendinous muscle.

The rats were sacrificed by an ether overdose and samples of the sciatic nerves were removed. The samples were collected 7 and 15 days after injection from the rats that received a single injection (group 1), and 10 days after injection from the rats submitted to multiple injections.

The samples were cut into three transverse fragments for light and transmission electron microscopy studies. All samples were washed with PBS, fixed in $2.5 \%$ glutaraldehyde in cacodylate buffer for $48 \mathrm{~h}$, postfixed in osmium tetroxide, dehydrated in graded ethanol solutions, and embedded in Epon 812 resin. Semi-thin sections were obtained with a Reichert Super Nova ultramicrotome with glass knives, stained with methylene blue and observed under a Meiji 2000 light microscope. Thin sections were made with diamond knives, stained with uranyl and lead salts and studied under an EM10 Zeiss transmission electron microscope operated at $60-80 \mathrm{kV}$.

\section{Results}

The rats injected with EB did not show any changes in either stance or gait during the experiment.

The localization of the lesions was facilitated by the stitch on the adjacent semitendinous muscle although a mild thickening of the epineurium was visible to the naked eye. This thickening was due to collagen proliferation observed in all lesions. Although some variation was detected, most of the lesions were 5-8 $\mathrm{mm}$ in length. All lesions showed segmental demyelination and extensive remyelination by Schwann cells. 
After intraneural injection of EB, Schwann cells showed signs of intoxication with a vacuolated cytoplasm and rejection of the myelin sheath. The sheaths showed condensation of the outer lamellae and progressive vesiculation leading to segmental demyelination. Myelin debris were removed by macrophages within the endoneurium distended by edema. Seven days after injection it was possible to observe the initial relationships of the naked axons with Schwann cells, some of them with intracytoplasmic myelin granules.

The axons were intact except those along the needle track which underwent Wallerian degeneration. Mast cells were conspicuous in the endoneurium of all lesions and occasionally lymphocytes and neutrophils were also detected.

From 15 days after injection a few supernumerary Schwann cells were observed in the endoneurium expanded by numerous collagen fibers. Groups of axons or axonal sprouts were wrapped by a basal lamina surrounded by collagen fibers (Figure 1). From 38 days after injection thin myelin sheaths had been deployed around most axons and the majority had redundant loops.

The nerves submitted to multiple injections showed degenerative (acute) lesions and regenerative (chronic) lesions (Figure 2). Acute lesions shared common features with lesions described at 7 and 15 days after injection.

Regenerated thin sheaths intermingled with sheaths of normal size were observed within chronic lesions. Endoneural expansion was greater because of the increased number of collagen fibers (Figure 3). After each EB injection, affected fibers showed a decreased diameter and myelin internodes appeared to be shorter, indicating the occurrence of a faster demyelination/remyelination process. The diminished diameter of the fibers together with the increased number of collagen fibers induced the formation of new fascicles composed of smaller numbers of thinner nervous fibers.

No inflammatory reaction or the formation of perivascular cuffings was observed in

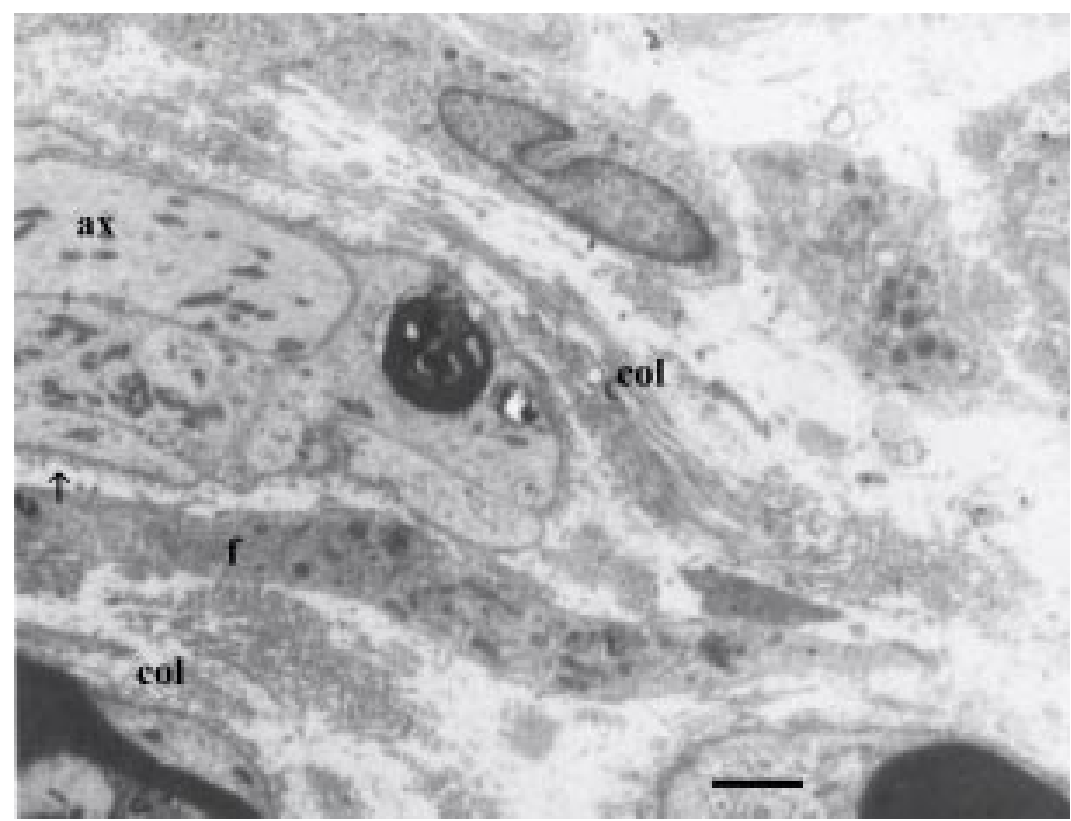

Figure 1. Transmission electronmicrograph of naked axons (ax) wrapped by a Schwann cell basal lamina (arrow) attached to collagen fibers (col); fibroblast (f). Lesion from group 2. Bar $=0.5 \mu \mathrm{m}$.

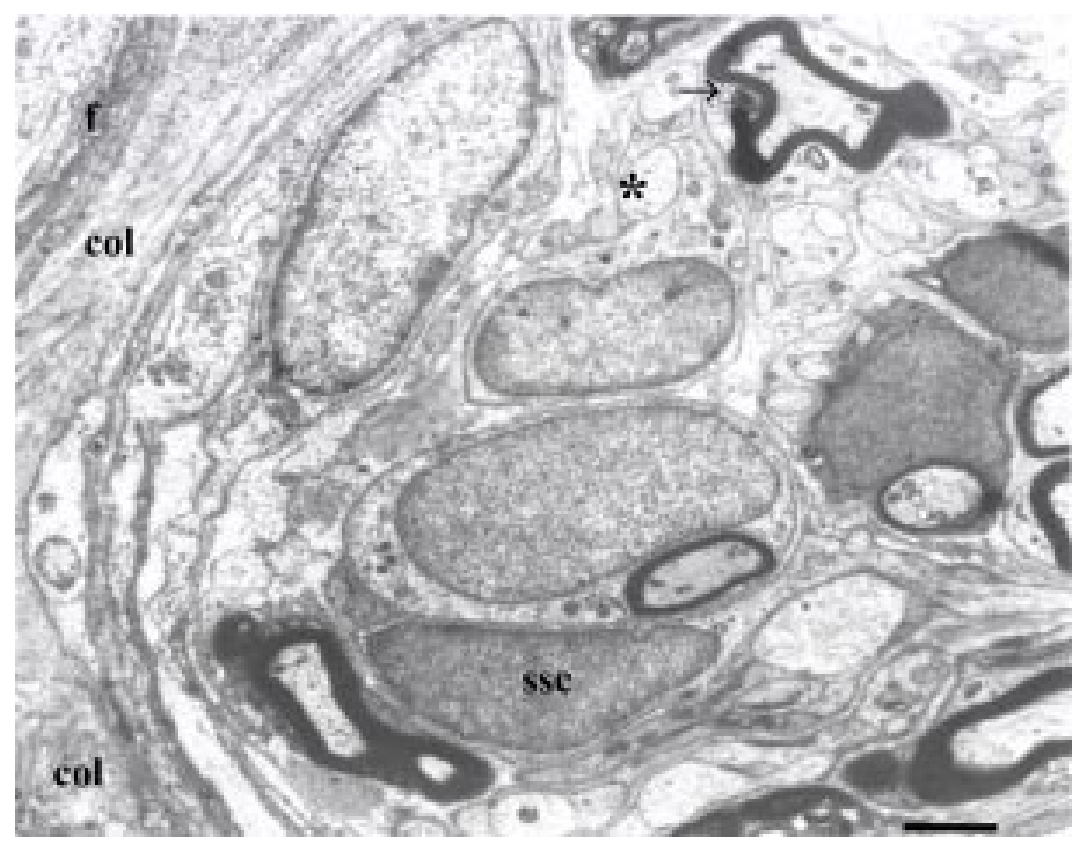

Figure 2. Transmission electronmicrograph of axons associated with Schwann cells: initial relationship (asterisk); remyelinated axons (arrow); supernumerary Schwann cell (SSC); collagen fibers (col); fibroblast (f). Lesion from group 3. Bar $=1 \mu \mathrm{m}$. 
any lesion. Control animals had Wallerian degeneration along the needle track and around the site of higher concentration of EB which was more marked in rats injected 6 and 8 times.

\section{Discussion}

EB injection into the PNS induced segmental demyelination followed by remyelination by Schwann cells like that observed in the CNS. The absence of clinical signs in the rats was attributed to the selection of a multifascicular nerve with a real possibility that some fascicles might have never been damaged by the drug or the needle.

In contrast to the CNS, there was no destruction of myelinating cells but rather intoxication of Schwann cells which soon after the injection rejected the sheaths that were extruded from their cytoplasm. Cavanagh (10) has pointed out the marked resistance of Schwann cells, stating that they are rarely destroyed, with their ability to maintain the internode being challenged and not their integrity.

The intoxicated Schwann cells exclude the internode that they surround completely and that functions like an organelle within their cytoplasm. Debris of the internode were

Figure 3. Transmission electronmicrograph of small diameter demyelinated axons (asterisk) associated with Schwann cells; some axons show a thin myelin sheath (arrows) whereas others are remyelinated with thicker sheaths and redundant loops (arrowhead). All fibers are separated by an increased deposition of collagen fibers (col). Lesion from group 5. Bar $=1 \mu \mathrm{m}$.

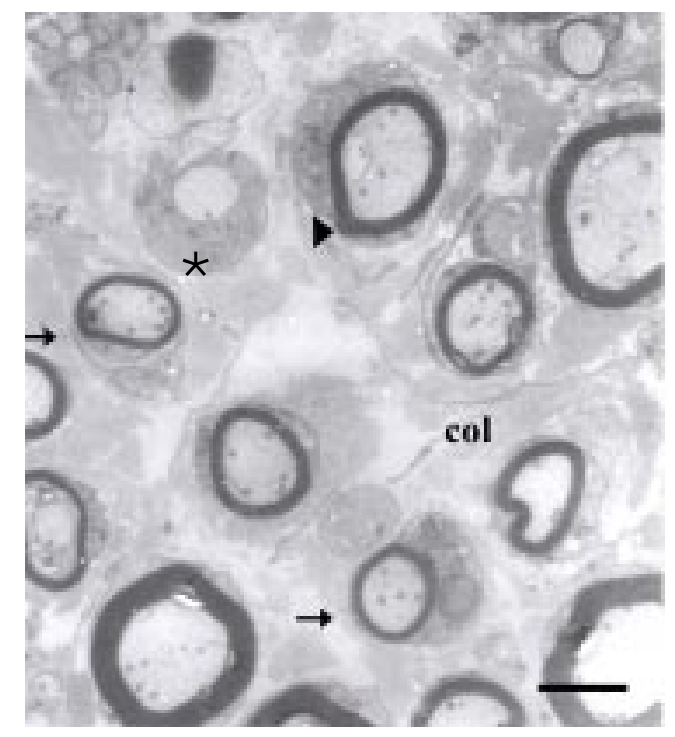

detected as dense cytoplasmic granules suggesting phagocytosed material instead of remains of a preexisting structure. Despite a long lasting discussion about the significance of Schwann cell phagocytic capacity in demyelination or Wallerian degeneration (11-13), the marked macrophage presence and the shortage of Schwann cell proliferation in the acute lesions of this investigation point to the limited share of the latter cells in debris removal after degeneration of the myelin sheaths.

The profuse macrophage activity and the activation of structural cells such as fibroblasts underlie the proliferation of collagen fibers characteristically observed within the lesions, after multiple injections. According to Fernández-Valle et al. (13), activated macrophages secrete molecules such as interleukin-1 and nerve growth factor which stimulate fibroblasts to produce and secrete collagen fibers, although Schwann cells may be able to produce collagen themselves (7).

The type of relationship between Schwann cells and the naked axons was similar in all lesions regardless of the number of injections and was the same as seen during myelination (14), with the axon governing the approach and commitment of the myelinating cell. The excess of myelin secretion seen as redundant loops in most internodes has been observed in natural processes such as metamorphosis (15) and in many experimental models of demyelination where the Schwann cell is the main myelinating cell (1).

The increased demyelination/remyelination rate observed in the present lesions has been reported in other experimental models such as after multiple local injections of lysolecithin into the sciatic nerve of Wistar rats (6). This increased rate proceeds after the progressive decrease of axonal diameter due to repeated demyelination and remyelination with thinner sheaths. If on the one hand collagen fibers help the proliferation, differentiation and myelinating function of 
Schwann cells, on the other, such an abundance of fibers might exert an anomalous pressure over the fibers. It has been suggested that axonal narrowing such as that occurring in the lysolecithin model may be a response to the loss of myelin or may be due to some interference with the normal Schwann cell/axon relationship (11). Such interference, if it really existed, did not lead to the formation of the "onion bulbs" observed in progressive or recurrent polyneuropathies $(16,17)$ or to the occurrence of hypoor dysmyelination similar to that reported in the quaking and Trembler mouse mutants in which the communication between Schwann cells and axons is genetically disturbed $(18,19)$.

The presence of mast cells in all lesions cannot be explained. Cavanagh (10) mentions the proliferation of mast cells in any pathology involving peripheral nerves without giving clues for their function. Krüger et al. (20) reported the presence of mast cells within multiple sclerosis plaques and, because of the proximity to blood vessels, suggested that these cells could be related to the blood-brain barrier. In the EB-induced lesions in the sciatic nerve there was no specific relationship between mast cells and blood vessels and therefore their function in the lesions remains obscure. However, in view of their conspicuous presence in all lesions, these cells may have some effect within the tissue that deserves further investigation.

The EB model of demyelination in the PNS allowed the observation that Schwann cells keep their potential to remyelinate repeatedly demyelinated axons without alterations in their communication with them.

The sciatic nerve as a whole changes its response to multiple episodes of demyelination since after every injection new fascicles formed, composed of progressively smaller numbers of thinner fibers separated by increasing numbers of collagen fibers. This toxic model proved to be efficient in the PNS as it has proved in the CNS and could be used as an experimental model of recurrent PNS conditions.

\section{Acknowledgments}

The authors wish to thank Ms. Rosmarina Passos Correa, Ms. Fabiana Gonçalves da Rosa and Ms. Simone Silveira da Silva for excellent technical assistance.

\section{References}

1. Graça DL, Bondan EF, Pereira LAV, Fernandes CG \& Maiorka PC (2001). Behavior of oligodendrocytes and Schwann cells in an experimental model of toxic demyelination of the central nervous system. Arquivos de Neuro-Psiquiatria, 59: 358361.

2. Pereira LAV, Dertkigil MSJ , Graça DL \& Cruz-Höfling MA (1998). Dynamic of remyelination in the brain of adult rats after exposure to ethidium bromide. J ournal of Submicroscopic Cytology and Pathology, 30: 341-348.

3. Bondan EF, Lallo MA, Sinhorini IL, Pereira LAV \& Graça DL (2000). The effect of cyclophosphamide on brainstem remyelination following local ethidium bromide injection in Wistar rats. J ournal of Submi- croscopic Cytology and Pathology, 32: 431-438.

4. Graça DL \& Blakemore WF (1986). Delayed remyelination in rat spinal cord following ethidium bromide injection. Neuropathology and Applied Neurobiology, 12: 593-605.

5. Fernandes CG, Graça DL \& Pereira LAVD (1997). Desmielinização e remielinização após múltiplas injeções intramedulares de brometo de etídio em ratos Wistar. Arquivos de Neuro-Psiquiatria, 55: 452-459.

6. Hall SM (1983). The response of the (myelinating) Schwann cell population to multiple episodes of demyelination. J ournal of Neurocytology, 12: 1-12.

7. Bunge RP (1993). Expanding roles for the Schwann cell: ensheathment, myelina- tion, trophism and regeneration. Current Opinion in Neurobiology, 3: 805-809.

8. Horner PJ \& Cage FH (2000). Regenerating the damaged central nervous system. Nature, 407: 963-970.

9. Bunge RP (1994). The role of the Schwann cell in trophic support and regeneration. J ournal of Neurology, 241: S19-S21.

10. Cavanagh J B (1990). Reaction of neurons and Schwann cells to injury. In: Weller RO (Editor), Nervous System, Muscle and Eyes. 3rd edn. Churchill Livingstone, London, England, 4: 533-543.

11. Hall SM (1973). Some aspects of remyelination after demyelination produced by the intraneural injection of lysophosphatidyl choline. J ournal of Cell Science, 13: 461-477. 
12. Beuche $W \&$ Friede $R L$ (1984). The role of non-resident cells in Wallerian degeneration. J ournal of Neurocytology, 13: 767796.

13. Fernández-Valle $C$, Bunge RP \& Bunge MB (1995). Schwann cells degrade myelin and proliferate in the absence of macrophages: evidence from in vitro studies of Wallerian degeneration. J oumal of Neurocytology, 24: 667-679.

14. Graça DL (1988). Mielinização, desmielinização e remielinização no sistema nervoso central. Arquivos de Neuro-Psiquiatria, 46: 292-297.

15. Cullen MJ \& Webster H deF (1979). Remodelling of optic nerve myelin sheaths and axons during metamorphosis in Xenopus laevis. J ournal of Comparative Neurology, 184: 353-362.

16. Goldstein J M, Parks BJ , Mayer PL, Kim J H, Sze G \& Miller RG (1996). Nerve root hypertrophy as the cause of lumbar stenosis in chronic inflammatory demyelinating polyradiculoneuropathy. Muscle and Nerve, 19: 892-896.

17. Bouche $P, M$ aisonobe $T \&$ Léger JM (1996). Les polyradiculonévrites inflammatoires chroniques idiopathiques. Revue Neurologique, 152: 365-369.

18. Quarles $\mathrm{RH}$, Morell $\mathrm{P} \&$ McFarlin DE (1994). Diseases involving myelin. In: Siegel GJ (Editor), Basic Neurochemistry:
Molecular, Cellular and Medical Aspects. 5th edn. Raven Press, New York, NY, USA, 771-792.

19. Bo L, Quarles RH, Fujita N, Bartoszewicz Z, Sato S \& Trapp BD (1995). Endocytic depletion of L-MAG from CNS myelin in quaking mice. J ournal of Cell Biology, 131 (6Pt2): 1811-1820.

20. Krüger $P G$, Bo $L$, Myhr KM, Karlsen $A E$, Taule A, Nyland HI \& Morsk S (1990). Mast cells and multiple sclerosis: a light and electron microscopic study of mast cells in multiple sclerosis emphasizing staining procedures. Acta Neurologica Scandinavica, 82: 31-36. 